ARTICLE

DOI: $10.1038 / s 41467-018-06202-4$

OPEN

\title{
Strobilurin biosynthesis in Basidiomycete fungi
}

\author{
Risa Nofiani ${ }^{1}{ }^{2}$, Kate de Mattos-Shipley ${ }^{1}$, Karen E. Lebe ${ }^{3,4}$, Li-Chen Han ${ }^{1}{ }^{1}$, Zafar Iqbal1,5, Andrew M. Bailey ${ }^{6}$, \\ Christine L. Willis (1) ${ }^{1}$, Thomas J. Simpson ${ }^{1}$ \& Russell J. Cox (10) 1,3,4
}

Strobilurins from fungi are the inspiration for the creation of the $\beta$-methoxyacrylate class of agricultural fungicides. However, molecular details of the biosynthesis of strobilurins have remained cryptic. Here we report the sequence of genomes of two fungi that produce strobilurins and show that each contains a biosynthetic gene cluster, which encodes a highly reducing polyketide synthase with very unusual $\mathrm{C}$-terminal hydrolase and methyltransferase domains. Expression of stpks 1 in Aspergillus oryzae leads to the production of prestrobilurin $A$ when the fermentation is supplemented with a benzoyl coenzyme $A(C o A)$ analogue. This enables the discovery of a previously unobserved route to benzoyl $\mathrm{CoA}$. Reconstruction of the gene cluster in $A$. oryzae leads to the formation of prestrobilurin $A$, and addition of the gene str9 encoding an FAD-dependent oxygenase leads to the key oxidative rearrangement responsible for the creation of the $\beta$-methoxyacrylate toxophore. Finally, two methyltransferases are required to complete the synthesis.

\footnotetext{
${ }^{1}$ School of Chemistry, University of Bristol, Cantock's Close, Bristol BS8 1TS, UK. ${ }^{2}$ Department of Chemistry, Faculty of Mathematics and Natural Sciences, University of Tanjungpura, J. Prof. Dr. H. Hadari Nawawi, Pontianak 78124, Indonesia. ${ }^{3}$ Institute for Organic Chemistry, Leibniz Universität Hannover, Schneiderberg 1B, 30167 Hannover, Germany. ${ }^{4}$ BMWZ, Leibniz Universität Hannover, Schneiderberg 38, 30167 Hannover, Germany. ${ }^{5}$ Department of Agricultural Chemistry, Faculty of Nutrition Sciences, The University of Agriculture, Peshawar 25130 Khyber Pakthunkhwa, Pakistan. ${ }^{6}$ School of Biological Sciences, University of Bristol, 24 Tyndall Avenue, Bristol BS8 1TH, UK. Correspondence and requests for materials should be addressed to R.J.C. (email: russell.cox@oci.uni-hannover.de)
} 
S trobilurin A $\mathbf{1}^{1}$ and oudemansin A $\mathbf{2}^{2}$ (also known as mucidin) are antifungal polyketides produced by various Basidiomycete fungi (Fig. 1a). The key $\beta$-methoxyacrylate toxophore targets the Qo site of complex III of the mitochondrial electron transport chain and prevents adenosine triphosphate synthesis $^{3}$. The major class of $\beta$-methoxyacrylate agricultural fungicides were developed from the structures of $\mathbf{1}$ and $\mathbf{2}$ with the aim of increasing photo-stability and selectivity. Thus, compounds such as azoxystrobin 3 (Syngenta) and Kresoxim methyl 4 (BASF) are among the most widely used fungicides worldwide. This class of antifungals are used as effective treatments against a broad range of destructive fungal plant pathogens and make significant contributions to food security 4,5 . The strobilurin fungicides are estimated to have been worth $\$ 3.4$ billion in 2015 and they make up $25 \%$ of the fungicide market and $6.7 \%$ of the total crop protection market. Numerous functionalised strobilurin natural products are known $^{6}$ in which the aromatic ring is hydroxylated (e.g. strobilurin F 5) ${ }^{7}$ and chlorinated (e.g. strobilurin B 6) ${ }^{1}$ and the hydroxyl groups can be, in turn, methylated or prenylated (e.g. strobilurin $G 7)^{7,8}$. Other compounds such as the formally reduced congener bolineol $\mathbf{8}^{9}$ have also been reported. Surprisingly, despite the high level of interest in the strobilurins as agricultural fungicides, remarkably little is known of their detailed biosynthesis.

Isotopic feeding experiments have shown that strobilurin A $\mathbf{1}^{10}$ and oudemansin A $2^{11}$ are polyketides, unusually derived from a

a<smiles>CO/C=C(C(=O)OC)\C(C)=C/C=C/c1ccccc1</smiles><smiles>CO/C=C(/C(=O)OC)C(C)[C@@H](/C=C/c1ccccc1)OC</smiles><smiles>CO/C=C(/C(=O)OC)c1ccccc1Oc1cc(Oc2ccccc2C#N)ncn1</smiles><smiles>CO/N=C(/C(=O)OC)c1ccccc1COc1ccccc1C</smiles><smiles>CO/C=C(C(=O)OC)/C(C)=C\C=C\c1cccc(O)c1</smiles><smiles>COC=C(C(=O)OC)/C(C)=C\C=C\c1ccc(Cl)c(OC)c1</smiles><smiles>CO/C=C(C(=O)OC)/C(C)=C\C=C\c1ccc2c(c1)OC(C)(C)C(OCC=C(C)C)CO2</smiles>

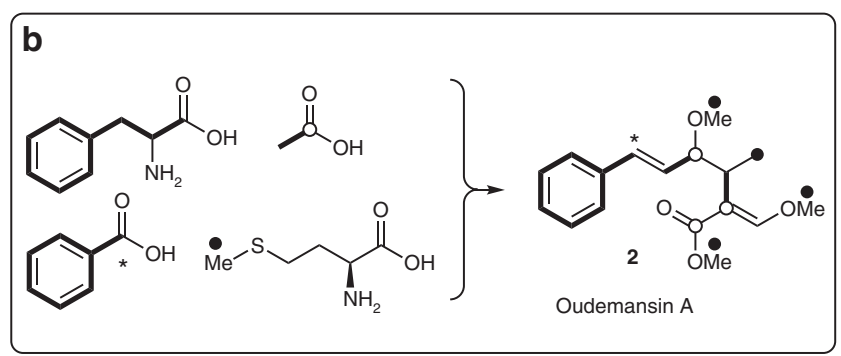

Fig. 1 Structures of key natural $(\mathbf{1}, \mathbf{2}, \mathbf{5 - 8})$ and synthetic $(\mathbf{3}, \mathbf{4})$ strobilurins. a Compounds 1-3 and 5-7 feature the key $\beta$-methoxyacrylate toxophore, while $\mathbf{8}$ is reduced. Compound $\mathbf{4}$ possesses a chemically similar methoxyiminoacetate toxophore; $\mathbf{b}$ incorporation of biosynthetic precursors into oudemansin A. Origin of atoms as indicated by bold bonds, and open and closed circles benzoate starter unit derived by the degradation of phenylalanine via cinnamate. In fungi, polyketides are produced by iterative polyketide synthase (PKS) enzymes that extend acyl coenzyme A (CoA) starter units using decarboxylative Claisen-type reactions with malonyl $\mathrm{CoA}^{12}$. The isotopic labelling patterns of $\mathbf{1}$ and 2 are consistent with three extensions of a benzoate starter unit and $C$-methylation of the chain (Fig. 1b) using $S$-adenosyl methionine (SAM). An unusual oxidative rearrangement is involved in the formation of the core $\beta$-methoxyacrylate, and $O$-methylations must also occur to give strobilurin A $\mathbf{1}$ and oudemansin A 2 . However, the molecular basis for these reactions has remained unexplored.

Here we reveal the biosynthetic gene cluster (BGC) responsible for the construction of the strobilurins and reconstruct the biosynthesis of $\mathbf{1}$ in the heterologous host Aspergillus oryzae. This reveals an unusual type of fungal PKS and the enzyme responsible for the key oxidative rearrangement reaction.

\section{Results}

The strobilurin BGC. Strobilurins have been reported mainly as products of Basidiomycete fungi such as Strobilurus tenacellus, but one apparent Ascomycete, Bolinea lutea, is also reported as a producer of a range of strobilurins and related compounds such as bolineol $8^{8}$. In our hands $S$. tenacellus produced strobilurin A 1 (typically $30 \mathrm{mg} \mathrm{L}^{-1}$ under optimised conditions), B 6 and G 7, and B. lutea $\mathrm{F} 23523^{7}$ reliably produced strobilurin B 6 (ca $1 \mathrm{mg} \mathrm{L}$ ${ }^{-1}$ ) in shake-flask culture. We sequenced the genomes of each organism to produce draft genomes using standard Illumina paired-end methodology (Supplementary Figure 1, Supplementary Tables 1-3). The $S$. tenacellus assembly produced a draft genome of $40.5 \mathrm{Mb}$ with an $\mathrm{N}_{50}$ of $121.3 \mathrm{~kb}$, while the $B$. lutea genome had a total size of $42.6 \mathrm{Mb}$ and an $\mathrm{N}_{50}$ of $63.5 \mathrm{~kb}$. The data are consistent with a conclusion that the organism previously known as $B$. lutea is, in fact, a Basidiomycete, and sequence analysis of its internal transcribed spacer sequence showed it to be most likely a previously unreported member of the Strobilurus family (Supplementary Figure 8). We thus rename it Strobilurus lutea.

Since fungal BGCs are usually relatively compact (often $<50$ $\mathrm{kb}$ ) the assemblies were considered sufficient to search for genes potentially involved in the biosynthesis of $\mathbf{1}$ and its derivatives. Anti-SMASH software ${ }^{13}$ identified two potential PKS-encoding BGCs in each genome (Supplementary Figure 6). The first of these encodes the expected type I iterative PKS typical of fungi ${ }^{12}$, and nearby are genes predicted to encode proteins involved in phenylalanine metabolism (for example, a phenylalanine ammonia lyase, PAL), methylation and redox reactions. The second cluster in each fungus lacks these types of genes and was not considered further. Our initial analysis showed that the S. lutea BGC is contained on one scaffold (SL-298) of $106 \mathrm{~kb}$. In contrast, the homologous PKS cluster in S. tenacellus is located on a smaller scaffold of only $30 \mathrm{~kb}$ (ST-273), suggesting that although this scaffold aligns well with the $S$. lutea cluster it may only represent a partial cluster. Data from the longer SL-298 scaffold was then used to search the $S$. tenacellus data for the missing genes and scaffold-195 (ST-195, ca $145 \mathrm{~kb}$ ) was identified as containing a number of homologues. Oligonucleotide primers designed based on the terminal sequences of ST-195 and ST-273 were used in a PCR reaction with $S$. tenacellus genomic DNA as the template and this yielded a ca $4 \mathrm{~kb}$ product, which was sequenced. The sequence closed the gap between ST-273 and ST195 demonstrating that these two scaffolds are genuinely adjacent genomic loci and represent separate parts of the same gene cluster. The total size of the combined $S$. tenecellus scaffold was $179.2 \mathrm{~kb}$ (Fig. 2). 


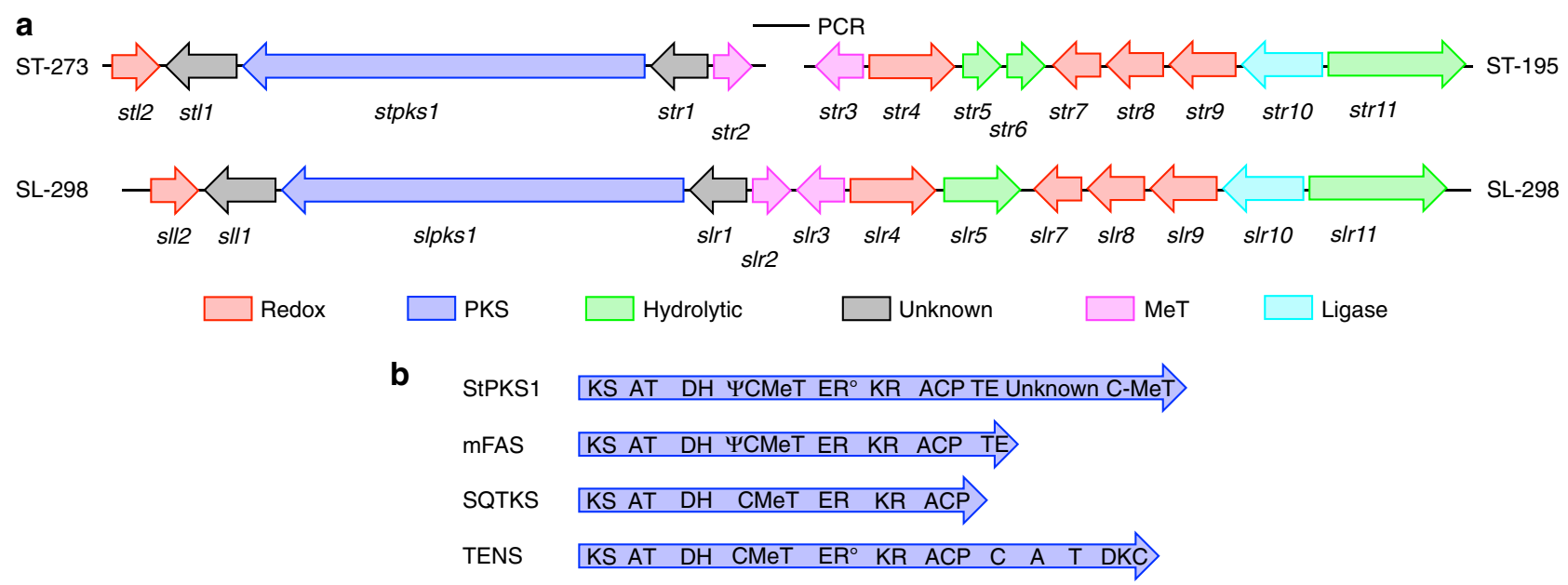

Fig. 2 Map of the strobilurin biosynthetic gene clusters in S. tenacellus and S. lutea. a Annotated ca $47 \mathrm{~kb}$ biosynthetic gene clusters contained in the S. tenacellus and S. lutea genomes (not to scale); b domain structure of known fungal highly reducing polyketide synthases. KS: keto-synthase, AT: acyltransferase, DH: dehydratase, C-MeT: C-methyltransferase; $\Psi C$-MeT: non-functional C-MeT, ER: enoyl-reductase, ER ${ }^{\circ}$ : non-functional ER, KR: ketoreductase, ACP: acyl carrier protein, TE: thiolesterase, C: condensation domain, A: adenylation domain, T: thiolation domain, DKC: Dieckmann cyclase, StPKS1: S. tenacellus polyketide synthase 1, mFAS: mammalian fatty acid synthase, SQTKS: squalestatin tetraketide synthase, TENS: tenellin synthetase

Basidiomycete genes usually contain numerous intron sequences, making automated gene-calling difficult. However, using predominantly manual methods, a total of 62 potential protein-encoding genes were identified and annotated between the overlapping scaffolds (Supplementary Table 5). In order to further clarify the data, Illumina transcriptome sequencing was performed using mRNA purified from $S$. tenacellus under strobilurin-producing conditions (Supplementary Figure 7). This refined the procedure of annotating the genes by confirming the transcriptional start and stop positions and the precise positions of introns, allowing correct coding sequences to be determined. Relative to the PKS, genes located downstream of the PKS are denoted $l$ (left) and genes upstream are denoted $r$ (right), and genes of S. tenacellus are denoted st, while genes of S. lutea are denoted $s l$. Thus, the gene $s l r 11$ is the eleventh identified gene to the right of the S. lutea PKS, and it encodes a PAL (Table 1).

We focussed our investigations on likely secondary metabolism genes immediately upstream and downstream of the PKS gene that appeared to be potentially involved in secondary metabolism (Fig. 2a). We therefore set the approximate cluster boundaries as stl2 downstream of the PKS and str11 upstream of the PKS, defining a ca $47 \mathrm{~kb}$ sequence for more detailed analysis. Resistance to strobilurins is known to be mediated by mutations in mitochondrial cytochrome b (encoded by $C Y T B)^{14,15}$. Whilst no homologues of $C Y T B$ were found within the cluster, or on the larger ST-195/273 or SL-298 scaffolds, we note that the mitochondrial $C Y T B$ shows motifs characteristic of being strobilurin resistant (see Supplementary Methods).

The PKS itself is encoded by a single large multi-exon coding sequence. Initial examination showed this to contain ketosynthase, acyl-transferase (AT), dehydratase (DH), C-methyltransferase $(C-\mathrm{MeT})$, enoyl-reductase (ER), keto-reductase (KR) and acyl carrier protein (ACP) domains, showing that it belongs to the fungal highly reducing class of PKS (hr-PKS, Fig. $2 b)^{12}$. Very unusually, the ACP is followed by a partial $\alpha \beta$-hydrolase domain closely related to the first 100 residues of the C-terminal thiolesterase (TE) of mammalian fatty acid synthase (mFAS, 33\% identical, $57 \%$ similar). This peptide sequence contains the conserved serine nucleophile (S2240) but not the cognate aspartate and histidine required by $\alpha \beta$-hydrolases. This sequence is followed by ca 300 residues with no significant sequence or structural homology to any known protein, although there is homology to predicted hr-PKS from other Basidiomycetes such as Stereum hirsutum (XP_007303267.1) and Gloeophyllum trabeum (XP_007863729.1, 37-41\% identity, 57-61\% similarity). The final 220 residues are homologous to SAM-dependent $C$-methyltransferases, including the CurJ $C$-MeT from curacin biosynthesis $(32 \% \text { identical, } 48 \% \text { similar })^{16}$. Detailed protein sequence comparisons with mFAS, the squalestatin tetraketide synthase $(\text { SQTKS })^{17}$ and tenellin synthetase (TENS) ${ }^{18}$ suggested that the $C$-MeT domain located between the $\mathrm{DH}$ and $\mathrm{KR}$ domains is probably inactive due to mutations in the SAM-binding motif, as is the ER, which is more similar to the inactive ER domain of TENS (Supplementary Figures 10-11). However, sequence analysis suggested that the C-terminal $\mathrm{C}$-MeT domain is likely to be active, as the SAM-binding site appears to be intact. The presence of all these domains as a single peptide was confirmed from the transcriptome data that showed a single transcript encoding the entire $306 \mathrm{kDa}$ protein (Supplementary Figure 12).

Other genes were functionally annotated by extensive manual comparisons to known genes from fungi, and while tentative functions could be proposed for most translated proteins, the roles of the $r 1$ and $l 1$ gene products remain enigmatic. A hydrolytic function encoded by $\operatorname{slr} 5$ as a single putative gene in the $S$. lutea genome appears to be formed as a fusion of two separate hydrolases encoded by str 5 and str 6 in the $S$. tenacellus genome. However, all other genes are encoded in the same relative positions and orientations in each cluster.

Heterologous expression of early pathway genes. We investigated expression of key genes from the cluster in A. oryzae ${ }^{19}$. Since the PKS is predicted to contain 28 introns, and the Ascomycete $A$. oryzae is unlikely to process all of these correctly ${ }^{20}$, we amplified intron-free fragments of stpks1 from cDNA, and reconstructed the entire $8.5 \mathrm{~kb}$ coding region of the PKS using recombination in yeast. The recombined intron-free stpks1 was cloned into the fungal expression vector pTYGS-Arg ${ }^{21}$, which was, in turn, transformed into A. oryzae strain NSAR1, which harbours four auxotrophic lesions on its genome allowing the introduction of up to four DNA fragments in parallel ${ }^{22-24}$. The pTYGS vector contains an $\arg B$ gene, which complements one of the auxotrophies, allowing selection on minimal media with appropriate supplements. The cloned gene of interest is expressed 


\section{Table 1 Detected genes located adjacent to pks1}

\begin{tabular}{|c|c|c|c|c|c|c|c|}
\hline Gene & $\begin{array}{c}\text { Strobilurus lutea } \\
\text { predicted protein function }\end{array}$ & $\mathrm{AA}$ & Gene & $\begin{array}{l}\text { Strobilurus tenacellus } \\
\text { predicted protein function }\end{array}$ & $\mathrm{AA}$ & $\begin{array}{c}\% \\
\text { Ident. }\end{array}$ & Predicted cofactor \\
\hline sll2 & SDR & 335 & $s t l 2$ & SDR & 340 & 97 & $\mathrm{NAD}(\mathrm{P})$ \\
\hline sll1 & Hypothetical protein & 499 & stll & Hypothetical protein & 498 & 84 & - \\
\hline slpks1 & PKS & 2815 & stpks 1 & PKS & 2824 & 93 & NAD(P), SAM \\
\hline $\operatorname{slrl}$ & Hypothetical protein & 404 & strl & Hypothetical protein & 207 & 82 & - \\
\hline$s l r 2$ & Methyltranferase & 269 & str2 & Methyltransferase & 275 & 95 & SAM \\
\hline$s l r 3$ & Methyltranferase & 332 & str 3 & Methyltransferase & 287 & 94 & SAM \\
\hline slr4 & GMCO & 600 & str 4 & GMCO & 632 & 95 & FAD \\
\hline $\operatorname{slr} 5$ & Hydrolase & 630 & $\begin{array}{l}\text { str } 5 \\
\text { str6 }\end{array}$ & $\begin{array}{l}\text { Hydrolase } 1 \\
\text { Hydrolase } 2\end{array}$ & $\begin{array}{l}278 \\
304\end{array}$ & - & $\begin{array}{l}- \\
-\end{array}$ \\
\hline$s l r 7$ & Aldoketoreductase & 336 & str7 & Aldoketoreductase & 336 & 96 & $\mathrm{NAD}(\mathrm{P})$ \\
\hline $\operatorname{slr} 8$ & NHI & 416 & str8 & NHI & 425 & 77 & $\mathrm{Fe}, \alpha$-ketoglutarate \\
\hline$s l r 9$ & FDO & 452 & $\operatorname{str} 9$ & FDO & 395 & 87 & FAD, NAD(P) \\
\hline slr10 & CoA ligase & 576 & str10 & CoA Ligase & 637 & 89 & ATP \\
\hline slr11 & PAL & 991 & str11 & PAL & 702 & 91 & - \\
\hline
\end{tabular}

See Supplementary Table 5 for a full list of genes found on the entire contig. Shaded rows indicate genes shown to be involved in the biosynthesis of strobilurin or bolineol by heterologous expression. Predicted functions from NCBI-conserved domain analysis

SDR: short-chain dehydrogenase, PKS: polyketide synthase, SAM S-adenosyl methionine, GMCO: glucose-methanol-choline oxidoreductase, PAL: phenylalanine ammonia lyase, NAD(P): nicotinamide adenine dinucleotide (phosphate), FAD: flavin adenine dinucleotide, ATP: adenosine triphosphate

under the control of the $a m y B$ promoter $\left(P_{a m y B}\right)$, which is induced, by starch and maltose ${ }^{25}$.

In initial experiments, expression of stpks1 alone in A. oryzae led to no significant changes in the metabolite profiles of transformed vs. untransformed strains (Table 2, expt 1). However, since benzoyl CoA is likely to be the starter unit for the biosynthesis of the expected strobilurin polyketide, and it is unknown whether $A$. oryzae can make this intermediate, we then supplemented fermentations with either benzoic acid or the $\mathrm{N}$ acetyl cysteamine thiolester of benzoic acid (benzoyl SNAC 9) ${ }^{26}$, which is a benzoyl CoA mimic. In these experiments a new compound 11 was produced in the presence of benzoyl SNAC 9 (Fig. 3a), but not benzoic acid 10 (Fig. 3b, Supplementary Figures 31-33) or in its absence (Fig. 3c) or in the control (Fig. 3d).

Analysis by liquid chromatography mass spectrometry (LCMS) showed that the new compound 11 had a mass $\left(m / z 215[\mathrm{M}] \mathrm{H}^{+}\right)$ consistent with a methylated tetraketide. The compound was isolated as a yellow powder $\left(20 \mathrm{mg} \mathrm{L}^{-1}\right)$. High-resolution mass spectrometry (HRMS, 213.0915, [M-H $]^{-}$) confirmed the molecular formula as $\mathrm{C}_{14} \mathrm{H}_{13} \mathrm{O}_{2}$ (calc. 213.0916). The structure was solved by analysis of one-dimensional and two-dimensional (2D) nuclear magnetic resonance (NMR) spectroscopy data (Fig. 3e, Supplementary Figure 34) that showed the presence of a monosubstituted benzene, two separate alkene spin systems with three and two protons respectively and a vinylic methyl group. Heteronuclear multiple bond correlation (HMBC) analysis showed the structure to be the triene 11, and observation of nOe between H-3 and H-6 suggested the Z-configuration of the central olefin. The other two olefins were determined to be $E$ from large vicinal coupling constants (ca $15.4 \mathrm{~Hz}$ ).

The structure and triene geometry was confirmed by total synthesis (Fig. 4). Briefly, the phenyl pyrone $12^{27}$ was reduced to the unsaturated lactone $\mathbf{1 3}$ that was then ring-opened by elimination to give the $E, Z$ triketide 14. Activation to the mixed anhydride/carbonate and reduction at low temperature gave the expected primary alcohol 15, which was oxidised to the corresponding aldehyde and subjected to Horner Wadsworth Emmons homologation. The resulting E,Z,E triene methyl ester was hydrolysed to give the corresponding tetraketide acid 11, which was identical (LCMS and NMR analysis, supplementary figure 34 ) to the material isolated from A. oryzae. Since this compound appears to be the first isolable intermediate in strobilurin biosynthesis we name it prestrobilurin A.

The apparent inability of A. oryzae to produce benzoyl CoA 16, or convert benzoic acid 10 to benzoyl CoA 16 then allowed us to probe the biosynthesis of this starter unit by using the PKS as a reporter for its presence. A second series of vectors was therefore constructed exploiting the adenine auxotrophy of $A$. oryzae NSAR1 and which contained combinations of str10, str8 and str11, which encode a CoA ligase, a non-haem iron oxygenase and a PAL respectively (see Supplementary Methods). Co-expression of stpks1 with str10 in A. oryzae (Table 2, expt 4) once again did not produce any new compounds, but feeding benzoic acid $\mathbf{1 0}$ to the fermentation resulted in the restoration of prestrobilurin A 11 production (Table 2, expt 5). Next, stpks1 was co-expressed with str10 and str 8 and again, in the absence of feeding this did not produce 11 (Table 2, expt 6). However, supplementation of either 
Table 2 Summary of heterologous expression experiments in A. oryzae designed to probe the biosynthesis of 1

\begin{tabular}{|c|c|c|c|c|c|c|c|c|c|c|c|c|c|}
\hline Construct & $\begin{array}{l}\text { stpks1 } \\
\text { PKS }\end{array}$ & $\begin{array}{l}\text { str11 } \\
\text { PAL }\end{array}$ & $\begin{array}{l}\text { str8 } \\
\text { NHI }\end{array}$ & $\begin{array}{l}\text { str10 } \\
\text { CoA ligase }\end{array}$ & $\begin{array}{l}\text { str9 } \\
\text { FDO }\end{array}$ & $\begin{array}{l}\text { str4 } \\
\text { GMCO }\end{array}$ & $\begin{array}{l}\text { st/2 } \\
\text { SDR }\end{array}$ & $\begin{array}{l}\text { str2 } \\
\text { Met1 }\end{array}$ & $\begin{array}{l}\text { str3 } \\
\text { Met2 } \\
\end{array}$ & 9 & 10 & 17 & Products \\
\hline Expt 1 & $\checkmark$ & - & - & - & - & - & - & - & - & - & - & - & Nothing \\
\hline Expt 2 & $\checkmark$ & - & - & - & - & - & - & - & - & - & $\checkmark$ & - & Nothing \\
\hline Expt 3 & $\checkmark$ & - & - & - & - & - & - & - & - & $\checkmark$ & - & - & 11 \\
\hline Expt 4 & $\checkmark$ & - & - & $\checkmark$ & - & - & - & - & - & - & - & - & Nothing \\
\hline Expt 5 & $\checkmark$ & - & - & $\checkmark$ & - & - & - & - & - & - & $\checkmark$ & - & 11 \\
\hline Expt 6 & $\checkmark$ & - & $\checkmark$ & $\checkmark$ & - & - & - & - & - & - & - & - & Nothing \\
\hline Expt 7 & $\checkmark$ & - & - & - & - & - & - & - & - & - & - & $\checkmark$ & Nothing \\
\hline Expt 8 & $\checkmark$ & - & $\checkmark$ & $\checkmark$ & - & - & - & - & - & - & - & $\checkmark$ & 11 \\
\hline Expt 9 & $\checkmark$ & - & $\checkmark$ & $\checkmark$ & - & - & - & - & - & - & $\checkmark$ & - & 11 \\
\hline Expt 10 & $\checkmark$ & $\checkmark$ & $\checkmark$ & $\checkmark$ & - & - & - & - & - & - & - & - & 11 \\
\hline Expt 11 & $\checkmark$ & $\checkmark$ & $\checkmark$ & $\checkmark$ & $\checkmark$ & $\checkmark$ & $\checkmark$ & $\checkmark$ & $\checkmark$ & - & - & - & $1,8,11,21$ \\
\hline Expt 12 & $\checkmark$ & $\checkmark$ & $\checkmark$ & $\checkmark$ & $\checkmark$ & $\checkmark$ & - & $\checkmark$ & $\checkmark$ & - & - & - & 1, 21 \\
\hline Expt 13 & $\checkmark$ & $\checkmark$ & $\checkmark$ & $\checkmark$ & - & $\checkmark$ & - & $\checkmark$ & $\checkmark$ & - & - & - & 11 \\
\hline Expt 14 & $\checkmark$ & - & - & - & - & $\checkmark$ & - & $\checkmark$ & $\checkmark$ & $\checkmark$ & - & - & 11 \\
\hline Expt 15 & $\checkmark$ & $\checkmark$ & $\checkmark$ & $\checkmark$ & $\checkmark$ & - & $\checkmark$ & - & - & - & - & - & 21,22 \\
\hline Expt 16 & $\checkmark$ & $\checkmark$ & $\checkmark$ & $\checkmark$ & $\checkmark$ & - & - & - & - & - & - & - & 21,22 \\
\hline Expt 17 & $\checkmark$ & $\checkmark$ & $\checkmark$ & $\checkmark$ & $\checkmark$ & - & - & $\checkmark$ & $\checkmark$ & - & - & - & $1,8,21,22$ \\
\hline Expt 18 & $\checkmark$ & $\checkmark$ & $\checkmark$ & $\checkmark$ & $\checkmark$ & - & $\checkmark$ & $\checkmark$ & $\checkmark$ & - & - & - & 8 \\
\hline
\end{tabular}

The indicated genes were co-expressed in A. oryzae in the presence of the indicated compounds

$\mathrm{NHI}$ : non-haem iron oxygenase, PAL: phenylalanine ammonia lyase, PKS: polyketide synthase, MeT: methyltransferase, GMCO: glucose-methanol-choline oxidase, FDO: flavin-dependent oxygenase, SDR: short-chain dehydrogenase/reductase

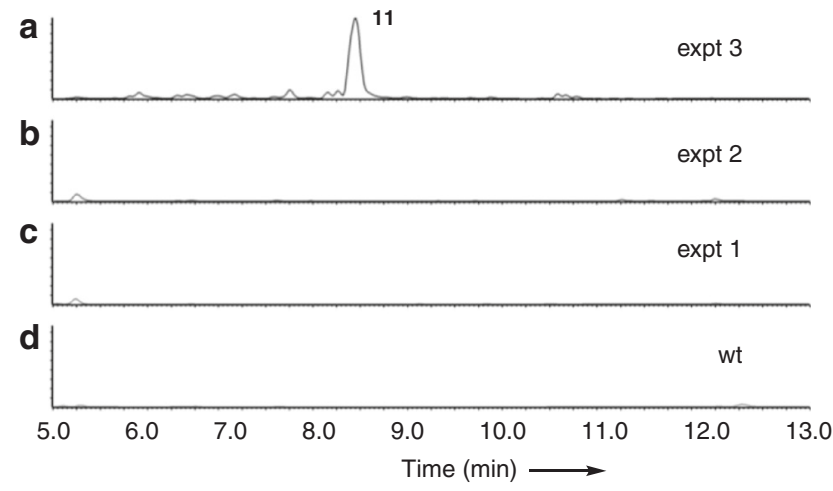

e<smiles>CC(=O)NCCSC(=O)c1ccccc1</smiles>

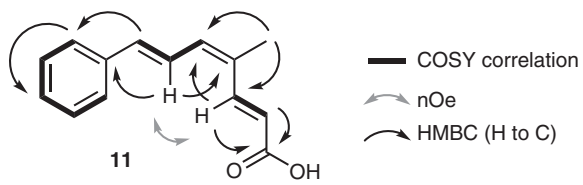

Fig. 3 In vivo activity of the strobilurin PKS encoded by stpks1. LCMS chromatograms (Diode Array Detector, DAD, 200-600 nm, arbitrary units) of extracts of $A$. oryzae NSAR1: a stpks1 + benzoyl SNAC $\mathbf{9} ; \mathbf{b}$ stpks1 + benzoic acid 10; c stpks1 alone; d WT NSAR1, LCMS method 1, LCMS liquid chromatography mass spectrometry. See Table 2 for details; e production of prestrobilurin A $\mathbf{1 1}$ by StPKS1. StPKS1 accepts benzoyl SNAC but not benzoic acid. Summary of 2D nuclear magnetic resonance (NMR) data

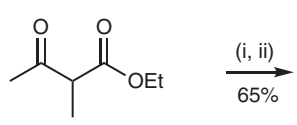<smiles>CC1=C(O)CC(c2ccccc2)OC1=O</smiles><smiles>CC(=CC=Cc1ccccc1)C(=O)O</smiles><smiles>CC1=CCC(c2ccccc2)OC1=O</smiles><smiles>[Y][14CH2][14CH2][14CH2]</smiles><smiles>C/C(=C/C=C/c1ccccc1)CO</smiles>

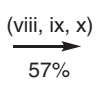<smiles>CC(=C/C=C/c1ccccc1)/C=C/C(=O)O</smiles>

Fig. 4 Total synthesis of prestrobilurin $\mathrm{A}$ 11. Reagents and conditions: $\mathrm{i}$ $\mathrm{PhCHO},{ }^{\mathrm{nBuLi}}$, $\mathrm{iPr}_{2} \mathrm{NH}, \mathrm{HMPA}, \mathrm{THF},-78^{\circ} \mathrm{C}$; ii $\mathrm{KOH}$ (aq); iii $\mathrm{Tf}_{2} \mathrm{O},{ }^{\mathrm{i}} \mathrm{Pr}_{2} \mathrm{EtN}$, $\mathrm{CH}_{2} \mathrm{Cl}_{2},-78{ }^{\circ} \mathrm{C}$; iv $\mathrm{Pd}\left(\mathrm{PPh}_{3}\right)_{4}, \mathrm{Et}_{3} \mathrm{SiH}, \mathrm{DMF}, 60^{\circ} \mathrm{C}$; v $\mathrm{Bu}_{4} \mathrm{NF}$, THF; vi EtOCOCl, Et $3 \mathrm{~N}, \mathrm{THF}, 0^{\circ} \mathrm{C}$; vii $\mathrm{NaBH}_{4}, \mathrm{MeOH}-78^{\circ} \mathrm{C}$; viii Dess-Martin periodinane, $\mathrm{CH}_{2} \mathrm{Cl}_{2}, \mathrm{RT}$; ix $(\mathrm{MeO})_{2} \mathrm{PCH}_{2} \mathrm{CO}_{2} \mathrm{Me}, \mathrm{NaH}, \mathrm{THF}, \mathrm{O}^{\circ} \mathrm{C}$ to $\mathrm{RT}$; $x \mathrm{NaOH}, \mathrm{THF}, \mathrm{H}_{2} \mathrm{O}$. RT room temperature

cinnamic acid $\mathbf{1 7}$ (Table 2, expt 8) or benzoic acid $\mathbf{1 0}$ (Table 2, expt 9), restored production of $\mathbf{1 1}$ (see supplementary methods). Finally, the $s t p k s 1, \operatorname{str} 10$, str8 and $s t r 11$ genes were co-expressed (Table 2, expt 10). In this case prestrobilurin A 11 was produced without the need to add intermediates, presumably because the PAL can convert endogenous phenylalanine $\mathbf{1 8}$ to cinnamate $\mathbf{1 7}$ 


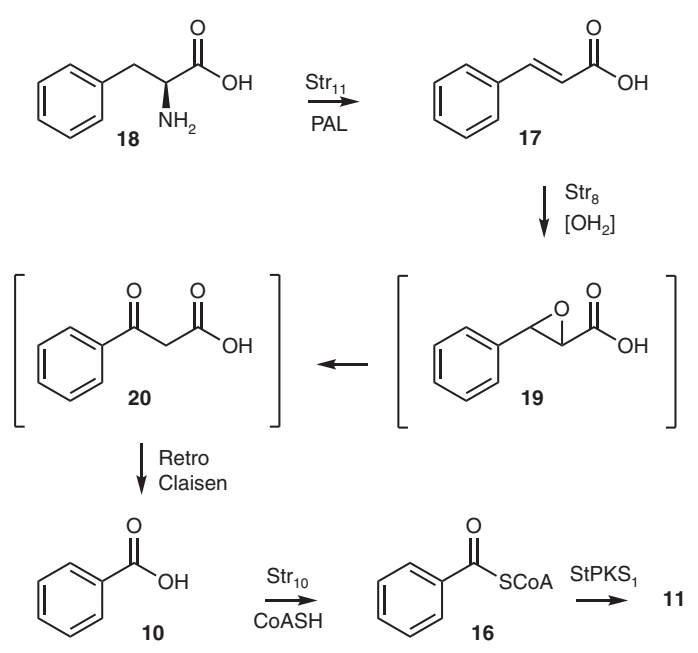

Fig. 5 Deduced biosynthetic pathway to benzoyl CoA in S. tenacellus. The pathway converts phenylalanine $\mathbf{1 8}$ to benzoyl CoA 16, which is then the substrate for StPKS1 to give prestrobilurin A 11

(Fig. 5). Thus, the plasmid pTYGS-Ade $\operatorname{str} 8+\operatorname{str} 10+\operatorname{str} 11$ acts as an effective source of in vivo benzoyl CoA.

Heterologous expression of later pathway genes. In order to investigate the later steps of strobilurin biosynthesis, additional genes were cloned into $A$. oryzae expression vectors (see supplementary methods). We reasoned that $s t r 2$ and str3, which encode SAM-dependent methyltransferases, are probably responsible for the addition of the two $O$-methyl groups of 1 . Oxidative rearrangement of $\mathbf{1 1}$ is required to create the skeleton of $\mathbf{1}$ and this may be achieved by either the glucose-methane-choline oxidase (GMCO) encoded by str4 or the flavin-dependent oxidase (FDO) encoded by str 9 . Finally, production of bolineol $\mathbf{8}$, observed in $S$. lutea, requires a reduction that may be achieved by the shortchain dehydrogenase (SDR) encoded by stl2.

In an initial heterologous experiment the full complement of genes, including the benzoyl CoA-production system (str8, str10 and str11), were transferred to A. oryzae (Table 2, expt 11). This resulted in production of 11 and $\mathbf{1}$ (retention time [Rt] $8.4 \mathrm{~min}$, $2.6 \mathrm{mg} \mathrm{L}^{-1}$, Fig. 6a) that was isolated and identified by full NMR analysis (Supplementary Figures 35-39). A new compound ( $\mathrm{Rt}=$ 7.1 min, $\mathrm{C}_{13} \mathrm{H}_{15} \mathrm{O}_{2}[\mathrm{M}+\mathrm{H}]^{+}$calc. 203.1072, measured 203.1071, Fig. 6a) was also isolated $\left(90 \mathrm{mg} \mathrm{L}^{-1}\right)$ and purified and shown to be the $5 E, 3 Z$ carboxymethyldiene 21 , which has been previously synthesised during the total synthesis of strobilurin A 1 (Fig. 7$)^{28}$. Bolineol 8 was detected to coelute with 21 by its distinctive [M + $\mathrm{H}]^{+}(247.1)$ and $[\mathrm{M}+\mathrm{Na}]^{+}(269.2)$ ions.

In a second experiment (Table 2, expt 12, Fig. 6b) the SDR was omitted and this led to a very similar result, but lacking bolineol 8. Omission of the FDO encoded by str9 (Table 2, expt 13, Fig. 6c) led to the production of only prestrobilurin A 11. The same result was achieved if the benzoate genes were omitted and the fermentation was supplemented with benzoyl SNAC 9 (Table 2, expt 14, Fig. 6d), although 11 is produced in much lower titre in this case.

Next, the methyltransferases and GMCO were omitted (Table 2, expt 15, Fig. 6e). This led to the formation of $\mathbf{2 1}$, and also a new compound 22 (Rt $5.9 \mathrm{~min}, 30 \mathrm{mg} \mathrm{L}^{-1}$ ), which was shown to be $\mathrm{C}_{14} \mathrm{H}_{16} \mathrm{O}_{3}$ ([M-H] $]^{-}$calc. 231.1021, measured 231.1021) by HRMS (Fig. 7). Isolation and full structure determination by NMR (Supplementary Figures 42-43) confirmed the new compound 22 to be desmethylbolineol. Desmethylbolineol 22

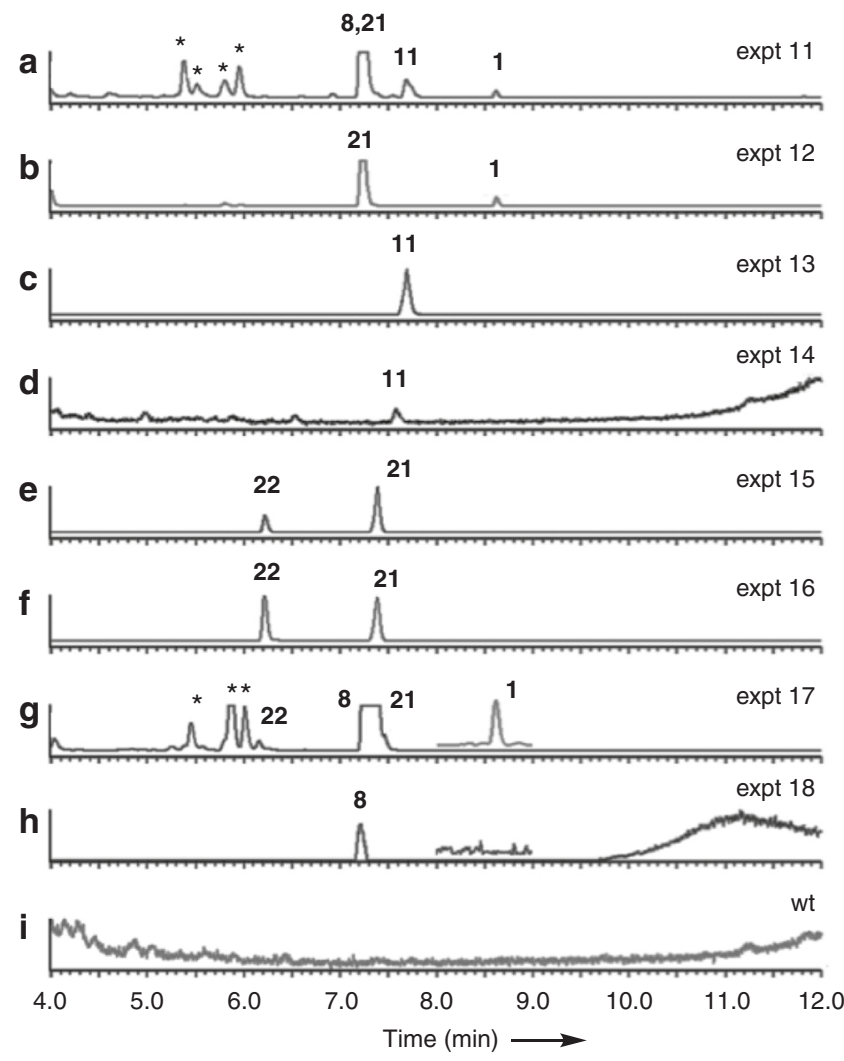

Fig. 6 LCMS evaporative light-scattering (ELS) chromatograms of organic extracts of $A$. oryzae NSAR1 expression strains (arbitrary units). a $A$. oryzae $\mathrm{NSAR} 1+\operatorname{stpks} 1+\operatorname{str} 2+\operatorname{str} 3+\operatorname{str} 4+\operatorname{str} 11+\operatorname{str} 8+\operatorname{str} 10+\operatorname{str} 9+\operatorname{st} 12 ; \mathbf{b} A$. oryzae NSAR1 + stpks1 + str2 + str3 + str4 + str11+str8+str10+str9; c $A$. oryzae NSAR1 + stpks $1+s t r 2+s t r 3+s t r 4+s t r 11+\operatorname{str} 8+\operatorname{str10;} \mathbf{d}$ A. oryzae NSAR1 + stpks1 + str2 + str3 + str4 + benzoyl SNAC 9; e A. oryzae NSAR1 + stpks $1+$ str11 + str8 + str10 + str9 + st12; f A. oryzae NSAR1 + stpks1+ str $11+\operatorname{str} 8+\operatorname{str} 10+\operatorname{str} 9 ; \mathbf{g}$ A. oryzae NSAR1 + stpks1 + str $2+$ str3 + str11 + str $8+\operatorname{str} 10+s t r 9$, inset trace shows extracted ion chromatogram for $\mathrm{m} / \mathrm{z}$ $259.1 ; \mathbf{h}$ A. oryzae NSAR1 + stpks1 + str $2+\operatorname{str} 3+\operatorname{str} 11+\operatorname{str} 8+\operatorname{str} 10+\operatorname{str} 9$ + st/2, inset trace shows extracted ion chromatogram for $m / z$ 259.1; i untransformed $A$. oryzae NSAR1. *Unrelated compounds. LCMS method 2. See Supplementary Figure 55 for additional data for expt 17

was smoothly converted to bolineol $\mathbf{8}$ by treatment with trimethylsilyldiazomethane ${ }^{29}$ and the spectroscopic data were shown to be identical. Further omission of the SDR (Table 2, expt 16, Fig. 6f) gave the same result, showing that formation of $\mathbf{2 2}$ does not require the SDR and must represent a shunt pathway in $A$. oryzae in the absence of the late-acting methyltransferases. Omission of the GMCO and SDR (Table 2, expt 17, Fig. 6g) resulted in extremely unhealthy $A$. oryzae cultures, which were difficult to select and grow (Supplementary Figure 55). Extraction of these cultures revealed the formation of bolineol $\mathbf{8}$ as the major compound, together with lesser amounts of 21 and 22. Strobilurin A 1 was detected by its distinctive mass spectrum, but in very low titre. Reinclusion of the SDR (Table 2, expt 18, Fig. 6h) produced $\mathbf{8}$ only, with no production of $\mathbf{1}$. No compounds were produced in the control experiment (Fig. 6i).

Finally, str9 was codon-optimised and expressed in Escherichia coli in N-terminal his-tagged form and purified in soluble form. The holo-protein, containing the FAD cofactor (verified by ultraviolet spectroscopy), was confirmed by mass spectrometry. Initial in vitro assays using purified prestrobilurin 11, purified Str9 and $\mathrm{NAD}(\mathrm{P}) \mathrm{H}$ in various buffers in air were performed, but 

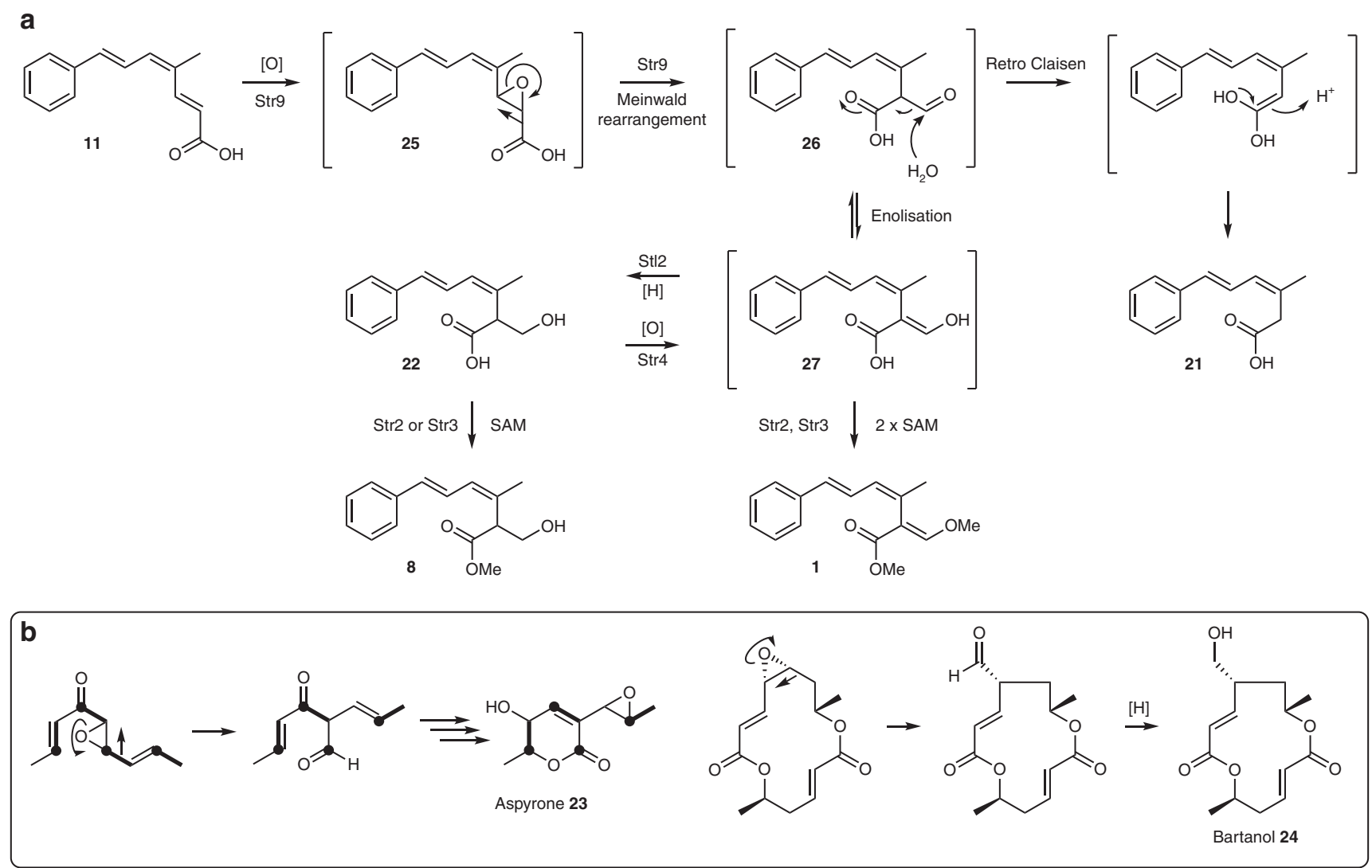

Fig. $\mathbf{7}$ Oxidative rearrangement of $\mathbf{1 1}$ on the pathway to $\mathbf{1}$ and shunts leading to observed compounds $\mathbf{2 1}$ and $\mathbf{2 2}$. a Deduced pathway from prestrobilurin $\mathbf{1 1}$ to strobilurin A 1. b Similar oxidative rearrangements observed during the biosynthesis of aspyrone $\mathbf{2 3}$ and bartanol $\mathbf{2 4}$

no oxidised and rearranged product $\mathbf{2 6}$ could be observed by LCMS analysis. We reasoned that this was most likely due to the observed insolubility of $\mathbf{1 1}$ in the aqueous buffer system. However, use of a system containing a high ethanol concentration, was more successful and a product corresponding to $\mathbf{2 6}$ was clearly observed by LCMS (Supplementary Figure 53).

\section{Discussion}

Our results show that biosynthesis begins with construction of benzoyl CoA 16 by step-wise elimination of ammonia from phenylalanine 18 (str11), oxygenation (str8) and retro-Claisen reaction to form benzoic acid $\mathbf{1 0}$, which is activated to its $\mathrm{CoA}$ thiolester 16 by a dedicated CoA ligase (str10, Fig. 5). Benzoyl CoA 16 then forms the starter unit for polyketide biosynthesis. Recent work by our group, and the group of Tang has shown that benzoyl CoA also forms the starter unit for the biosynthesis of the squalestatin hexaketide in Ascomycetes ${ }^{30,31}$. Although the two fungal pathways for the formation of benzoyl CoA share a common PAL enzyme, the squalestatin pathway involves formation of cinnamoyl CoA early in the pathway, while the strobilurin pathway is not consistent with the formation of cinnamoyl $\mathrm{CoA}$ as an intermediate, but appears to involve direct oxidative conversion of cinnamic acid $\mathbf{1 7}$ to benzoic acid $\mathbf{1 0}$.

Use of benzoate (and other non-acetate) starter units by fungal PKS is rare. Starter unit selection is presumably controlled by the AT domain of the PKS, however in the absence of structural data it is not yet possible to determine the basis of this selectivity. The strobilurin PKS appears to contain an inactive enoyl-reductase domain $\left(\mathrm{ER}^{\circ}\right)$ similar to the lovastatin nonaketide synthase $\mathrm{s}^{32}$ and the TENS ${ }^{33}$, but no gene encoding a trans-acting enoyl-reductase is present (e.g. $\operatorname{lov} C$ or ten $C$ ) and this is consistent with its synthesis of a triene. On the other hand, the strobilurin PKS is highly unusual among fungal hr-PKS in containing catalytic domains located after the ACP domain ${ }^{12}$. The presence of non-canonical catalytic domains such as $C$-MeT and reductive release domains is common for non-reducing PKS (e.g. methylorcinaldehyde synthase) ${ }^{34}$, but is more unusual for fungal hr-PKS, although non-ribosomal peptide ${ }^{35}$ and carnitine acyl-transferase ${ }^{36}$ mechanisms are known. The observed hydrolase domain of the strobilurin PKS may be responsible for release of prestrobilurin A 11, while the unique $\mathrm{C}$ terminal methyltransferase probably attaches the C-4 methyl group as sequence analysis suggests the more normally positioned $C-\mathrm{MeT}$ is inactive. Further work will be required to verify this hypothesis.

The strobilurins contain a highly unusual E,Z,E triene and the origin of this motif has been hitherto unexplained. Polyketides are already known, which have $Z$-olefins, for example, borrelidin, FR901464 and fostriecin. In the case of the modular borrelidin PKS, a DH domain creates a typical E-olefin, which is later isomerised ${ }^{37}$, while in the case of FR901464 a specialised TE domain rather than a $\mathrm{DH}$ domain, creates the $Z$-olefin ${ }^{38}$. In the case of the modular fostriecin PKS the DH from module 2 has been shown to create a $Z$-olefin directly ${ }^{39}$. Xie and Cane recently showed that in the cases of bongkrekic acid and oxazolomycin, produced by bacterial transAT PKS, a KR sets up a $\beta$-alcohol anti to an $\alpha$-proton and the subsequent syn dehydration gives the $Z$-olefin directly ${ }^{40}$. The only $\mathrm{KR} / \mathrm{DH}$ pair from a fungal hr-PKS investigated in vitro is from the SQTKS and this has a KR, which reduces to give the opposite alcohol diastereomer and the subsequent syn $\mathrm{DH}$ yields the $E$ olefin $^{41}$. The strobilurin PKS is unique in being an iterative type I system that creates the $Z$-olefin. Our results suggest that the strobilurin PKS installs this geometry without the requirement for any 

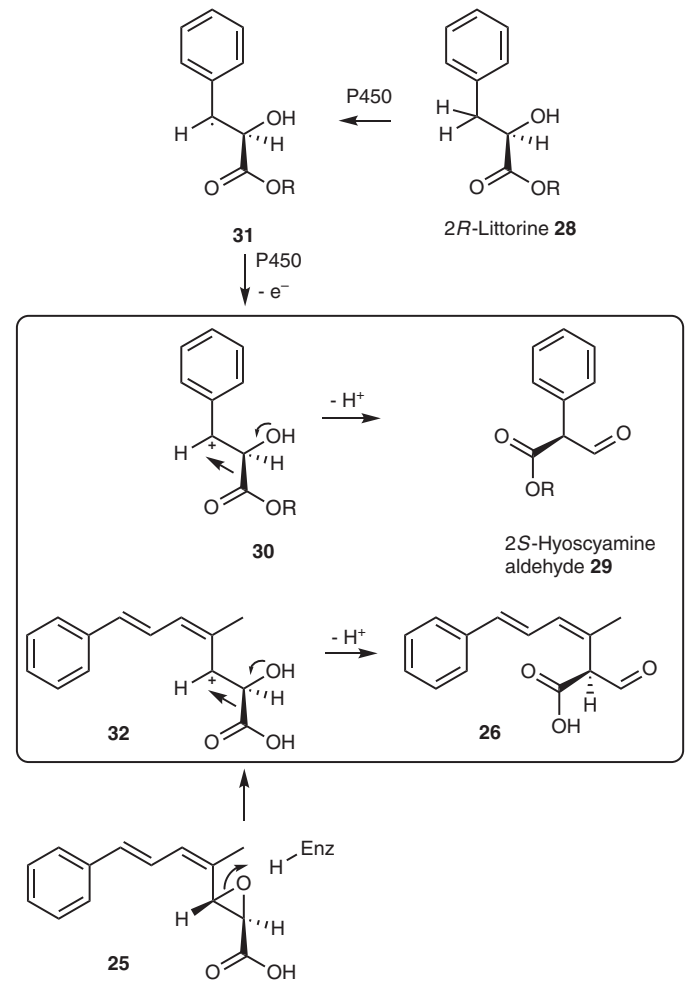

Fig. 8 Proposed mechanism of the strobilurin rearrangement and (boxed) comparison with a proposed cationic rearrangement mechanism of $2 R$ littorine. $R=3$-tropanyl

other proteins, so the KR/DH domains may be able to control different stereoselectivity during their first $(E)$, second $(Z)$ and third $(E)$ iterations, perhaps in response to methylation. Alternatively, the unknown domain of the strobilurin PKS may have a role in formation of the unusual $E, Z, E$ triene, but further detailed in vitro work will be required to determine its origin.

The released polyketide $\mathbf{1 1}$ requires oxidation and rearrangement to form the key acrylate moiety (Fig. 7a). Similar rearrangements have been suggested in the cases of aspyrone $\mathbf{2 3}^{42}$ and bartanol $24^{43}$ (Fig. 7b), and are also involved in ringcontracting mechanisms in the case of xenovulene $\mathrm{A}^{44,45}$. Tang and co-workers very recently reported a family of CrtC-type (carotenoid 1,2-hydratase) enzymes, which can catalyse rearrangements of epoxides. In the case of the CrtC-enzyme PenF this rearrangement is a Meinwald rearrangement on the pathway to penigequinolone. In our hands expression of the FADdependent monooxygenase encoded by str 9 in the presence of prestrobilurin A $\mathbf{1 1}$ effectively accomplishes the oxidative rearrangement in vivo involving the highly unusual migration of a carboxylate. This reaction is also observed in vitro. We propose that epoxidation of the 2,3 olefin of $\mathbf{1 1}$, followed by Meinwald rearrangement of $\mathbf{2 5}$ would furnish the aldehyde intermediate 26. This intermediate, however, seems to be highly reactive and in the absence of other enzymes it appears to undergo rapid retro-Claisen reaction to give the observed carboxylic acid 21 (Fig. 7a).

In Strobilurus species rapid enolisation of $\mathbf{2 6}$ would give the $\beta$-methoxyacrylate skeleton 27 and methylation (catalysed by Str2 and Str3) would give strobilurin A 1 directly. Further support for the intermediacy of $\mathbf{2 6}$ comes from the reductive pathway to $\mathbf{2 2}$ and bolineol $\mathbf{8}$. The reduction occurs both in the presence of Stl2 (expt 11, expt 18) and, in A. oryzae, absence of Stl2 (expt 17) likely due, at least in part, to a shunt pathway in A. oryzae, which is known to reduce aldehydes easily ${ }^{46}$. The FDO Str4 is a member of the GMCO superfamily, which are enzymes responsible for the oxidation of primary alcohols to aldehydes. In the presence of Str 4 and absence of the reductase Stl2, the pathway produces strobilurin A $\mathbf{1}$ and the shunt $\mathbf{2 1}$ (expt 12). In the absence of Str4, and the presence of Stl2, the pathway produces bolineol 8 instead (expt 18). This suggests that in S. tenacellus the pathway may be controlled to produce 1 or $\mathbf{8}$ selectively, possibly by control of the individual promoters. In our A. oryzae expression more crude control of the promoters (e.g. expt 11) produces both compounds. A possible pathway from $\mathbf{8}$ to $\mathbf{1}$ via alcohol oxidation and methylation is also possible, but we could find no LCMS evidence in support of the required mono-methyl intermediate.

The retro-Claisen removal of the $\beta$-aldehyde of $\mathbf{2 6}$ links this step to the proposed oxidative ring contractions involved during xenovulene A biosynthesis that are also catalysed by FADdependent enzymes ${ }^{45}$. However, bioinformatic analysis shows no significant homology between Str9 and AsR4 and AsR6 that are responsible for these reactions in Sarocladium schorii ${ }^{45}$. There is also no significant homology between Str9, or any other protein encoded by the str BGC, and PenF, suggesting that Str9 accomplishes both the oxidation of $\mathbf{1 1}$ and the rearrangement to form 26.

The proposed rearrangement mechanism involves the unusual migration of a carboxylate as proven by the isotopic labelling studies ${ }^{10}$. Similar processes are known, for example, during the mechanism of methylmalonate mutase and during the biosynthesis of the tropane alkaloid hyoscyamine from littorine $\mathbf{2 8}$ (Fig. 8). In the classic case of methylmalonate mutase the reaction is known to be adenosylcobalomin-dependent, and to proceed via single-electron species ${ }^{47}$. In the case of hyoscyamine biosynthesis a cytochrome P450 enzyme is known to catalyse the key rearrangement of littorine $\mathbf{2 8}$ to give $2 S$-hyoscyamine aldehyde $\mathbf{2 9}$. Calculations reported by Sandala et al. ${ }^{48}$ suggest that the lowestenergy pathway for this conversion involves rearrangement of a cationic species such as $\mathbf{3 0}$ obtained by facile oxidation of an intermediate radical 31, with acceleration promoted by partial deprotonation of the alcohol and partial protonation of the carboxyl. However, in vitro studies of the enzyme by O'Hagan and co-workers ${ }^{49}$ supported a rearrangement mechanism with more radical character. In the strobilurin rearrangement formation of radical intermediates seems unlikely and a cationic mechanism via e.g. 32 is consistent with other Meinwald processes ${ }^{50}$ and the calculations for the littorine $\mathbf{2 8}$ rearrangement to which it shows remarkable structural similarities (Fig. 8). However, further in vitro experiments will be required to definitively determine the mechanism.

Both S. lutea and S. tenacellus produce a range of modified strobilurins, including the chlorinated strobilurin B 6. However, the cluster encodes no obvious halogenase gene that could be involved in its production. Similarly, no obvious dimethylallyltransferase appears to be encoded within the currently determined BGC. This leaves the biosynthesis of compounds such as strobilurin G 7 as cryptic for the time being. It is possible that unknown proteins encoded in, or near, the BGC (e.g. str1 and stl1) may form new classes of halogenases or dimethylallytransferases, or that the responsible genes are located elsewhere on the genome. Similarly, proteins encoded by str $5 /$ str6 (hydrolases) appear to have no chemical role in the biosynthesis of $\mathbf{1}$. No obvious self-resistance gene was found within the cluster and this correlates with previous studies suggesting that the mitochondrial 
cytochrome $\mathrm{bc}_{1}$ complex of $S$. tenacellus is not inhibited by $\beta$-methoxyacrylates ${ }^{14}$ (see Supplementary Methods and Supplementary Figures $45-47$ for analysis of the resistance mechanism of S. lutea and S. tenacellus).

Overall, investigation of the strobilurin biosynthetic pathway in Strobilurus species has revealed how nature has generated this valuable class of fungicides, making use of: a previously unobserved biosynthetic pathway to benzoyl CoA 16; a class of highly reducing iterative fungal $\mathrm{PKS}$, which appears to include a very unusual partial hydrolase and $\mathrm{C}$-MeT domains located downstream of the usually terminal ACP, and which is capable of forming a highly unusual $E, Z, E$ triene; and a previously unobserved FAD-dependent oxygenase, which is responsible for the key oxidative rearrangement of a polyketide skeleton to form the crucial $\beta$-methoxyacrylate toxophore of the strobilurin fungicides. The use of heterologous expression once again illustrates the power of this method for the investigation and engineering of fungal BGCs. In our hands the unoptimised heterologous expression host produced over $100 \mathrm{mg} \mathrm{L}^{-1}$ of strobilurin-related metabolites compared to $30 \mathrm{mg} \mathrm{L}^{-1}$ in optimised WT fermentations.

\section{Methods}

Fermentation and extraction. S. tenacellus (strain CBS 621.79) and B/S. lutea F23523 were obtained from CBS-KNAW, Fungal Diversity Centre, Netherlands, and Novartis, Switzerland, respectively. A plug of fungi (S. tenacellus or S. lutea F23523) was inoculated into $100 \mathrm{~mL}$ malt extract broth in $500 \mathrm{~mL}$ Erlenmeyer flasks and incubated at $200 \mathrm{rpm}$ and $25^{\circ} \mathrm{C}$. After 10 days, the culture was homogenised by a hand blender and used as seed culture. The seed $\left(\mathrm{OD}_{600} 0.3\right)$ was inoculated in $100 \mathrm{~mL}$ of liquid medium (CGC or CMP) and incubated for the desired period. Each culture was then homogenised by hand blender and twice extracted with ethyl acetate with ratio $=1: 1 \mathrm{v} / \mathrm{v}$. The organic extracts were pooled, dried $\left(\mathrm{MgSO}_{4}\right)$, filtered and evaporated in vacuo. The residue was dissolved in methanol and defatted using $n$-hexane (two times) then evaporated in vacuo. Finally, the defatted residue was dissolved in highperformance liquid chromatography (HPLC)-grade methanol $\left(10 \mathrm{mg} \mathrm{mL}^{-1}\right)$ and analysed by LCMS.

A. oryzae NSAR1 and selected transformants were grown on malt extract agar (MEA) until sporulation (5-7 days), after which the spores were harvested in $5 \mathrm{~mL}$ sterilised $\mathrm{H}_{2} \mathrm{O}$ and used to inoculate production medium (CMP, $100 \mathrm{~mL}$ ). Cultures were grown for 6 days at $28^{\circ} \mathrm{C}$ with shaking at $200 \mathrm{rpm}$ before being homogenised by a hand blender and extracted twice with ethyl acetate $(1: 1 \mathrm{v} / \mathrm{v})$. The organic layer was separated, dried $\left(\mathrm{MgSO}_{4}\right)$, filtered and evaporated in vacuo. The extract was dissolved in methanol and defatted using $n$-hexane (two times) then evaporated in vacuo. Finally, the extract was dissolved in HPLC-grade methanol $\left(10 \mathrm{mg} \mathrm{mL}^{-1}\right)$ and analysed by LCMS. Samples for purification were prepared to $100 \mathrm{mg} \mathrm{mL}^{-1}$.

Media. All media were prepared in deionised water and autoclaved at $126^{\circ} \mathrm{C}$ for $20 \mathrm{~min}$. CMP, $3.5 \%$ Czapek Dox, $2 \%$ maltose and $1 \%$ peptone; CGC, $50 \mathrm{~g} \mathrm{~L}^{-1}$ glucose, $5 \mathrm{~g} \mathrm{~L}^{-1}$ corn steep liquor and $2 \mathrm{~g} \mathrm{~L}^{-1} \mathrm{CaCO}_{3} ; \mathrm{GN}, 1 \%$ glucose and $2 \%$ nutrient broth No. 2; CZST, 3.5\% Czapek Dox agar and $1 \mathrm{M}$ sorbitol; CZSB, 3.5\% Czapek Dox broth, $1 \mathrm{M}$ sorbitol and $0.8 \%$ agar; SMURA, $0.17 \%$ yeast nitrogen base, $0.5 \%$ ammonium sulphate, $2 \%$ glucose, $0.077 \%$ complete supplement mixture minus uracil and $1.5 \%$ agar; YM, $4 \mathrm{~g} \mathrm{~L}^{-1}$ yeast extract, $4 \mathrm{~g} \mathrm{~L}^{-1}$ glucose and $10 \mathrm{~g} \mathrm{~L}^{-1}$ malt extract; LB, $1 \%$ tryptone, $0.5 \%$ yeast extract and $0.5 \% \mathrm{NaCl}$; YPAD, $1 \%(\mathrm{w} / \mathrm{v})$ yeast extract, $2 \%$ bactotryptone, $2 \%(\mathrm{w} / \mathrm{v})$ glucose and $0.04 \%(\mathrm{w} / \mathrm{v})$ adenine sulphate; MEA, $15 \mathrm{~g} \mathrm{~L}^{-1}$ malt extract, $1.5 \mathrm{~g} \mathrm{~L}^{-1}$ arginine, $1.5 \mathrm{~g} \mathrm{~L}^{-1}$ methionine, $0.1 \mathrm{~g} \mathrm{~L}$ ${ }^{-1}$ adenine, $2 \mathrm{~g} \mathrm{~L}^{-1}$ ammonium sulphate and $15 \mathrm{~g} \mathrm{~L}^{-1}$ agar.

Analytical LCMS. LCMS data were obtained with either (LCMS method 1): a Waters 2795HT HPLC a Phenomenex Kinetex column $\left(2.6 \mu, \mathrm{C}_{18}, 100 \AA ., 4.6 \times 100 \mathrm{~mm}\right)$ equipped with a Phenomenex Security Guard precolumn (Luna $C_{5} 300 \AA$ ) eluted at $0.9 \mathrm{~mL} \mathrm{~min}^{-1}$, with a Waters 996 Diode Array detector between 200 and $600 \mathrm{~nm}$ and a Waters ZQ mass detector operating simultaneously in $\mathrm{ES}^{+}$and $\mathrm{ES}^{-}$modes between 100 and $650 \mathrm{~m} / z$; or (LCMS method 2) a Waters 2767 sample manager connected to Waters 2545 pumps and SFO, a Phenomenex Kinetex column $\left(2.6 \mu, \mathrm{C}_{18}, 100 \AA\right.$, $4.6 \times$ $100 \mathrm{~mm}$ ) equipped with a Phenomenex Security Guard precolumn (Luna $\mathrm{C}_{5} 300 \AA$ ) eluted at $1.0 \mathrm{~mL} \mathrm{~min}^{-1}$, with a waters 2998 Diode Array detector $(200-600 \mathrm{~nm})$ and Waters 2424 ELSD and Waters SQD-2 mass detector operating simultaneously in ES + and $\mathrm{ES}^{-}$modes between 100 and $650 \mathrm{~m} / z$. Solvents were: A, HPLC-grade $\mathrm{H}_{2} \mathrm{O}$ containing $0.05 \%$ formic acid; B, HPLC-grade $\mathrm{MeOH}$ containing $0.045 \%$ formic acid; and $\mathrm{C}$, HPLC-grade $\mathrm{CH}_{3} \mathrm{CN}$ containing $0.045 \%$ formic acid. The gradient was as follows: $0 \mathrm{~min}, 10 \% \mathrm{C} ; 10 \mathrm{~min}, 90 \% \mathrm{C} ; 12 \mathrm{~min}, 90 \% \mathrm{C} ; 13 \mathrm{~min}, 10 \% \mathrm{C}$; and $15 \mathrm{~min}$, $10 \% \mathrm{C}$

Compound purification. Purification of all compounds was generally achieved using a Waters mass-directed autopurification system comprising of a Waters 2767 autosampler, Waters 2545 pump system, a Phenomenex Kinetex Axia column $(5 \mu$, $\mathrm{C}_{18}, 100 \AA, 21.2 \times 250 \mathrm{~mm}$ ) equipped with a Phenomenex Security Guard precolumn (Luna $\mathrm{C}_{5} 300 \AA$ ) eluted at $20 \mathrm{~mL} \mathrm{~min}{ }^{-1}$ at ambient temperature. Solvents as above. The post-column flow was split (100:1) and the minority flow was made up with HPLC-grade $\mathrm{MeOH}+0.045 \%$ formic acid to $1 \mathrm{~mL} \mathrm{~min}^{-1}$ for simultaneous analysis by diode array (Waters 2998), evaporative light-scattering (Waters 2424) and electrospray ionisation mass spectrometry in positive and negative modes (Waters SQD-2). Detected peaks were collected into glass test tubes. Combined fractions were evaporated (vacuum centrifuge), weighed and residues dissolved directly in deuterated solvent for NMR.

Construction of expression plasmids. All construction details are given in the Supplementary Methods.

Transformation of $\boldsymbol{A}$. oryzae NSAR1. Spores of A. oryzae NSAR1 were prepared by inoculation of the fungus onto MEA plates and incubation at $30^{\circ} \mathrm{C}$ for 1-2 weeks or until sporulation occurred. The spores were harvested from plates and inoculated into GN medium then incubated at $28^{\circ} \mathrm{C}$ with shaking $200 \mathrm{rpm}$ overnight. The culture was harvested by centrifugation at $8000 \times g$ for $10 \mathrm{~min}$ and the supernatant discarded. The pellet was washed once with sterilised water and once with sterile $0.8 \mathrm{M} \mathrm{NaCl}$. The pellet was resuspended in $10 \mathrm{~mL}$ of filter sterilised protoplasting solution $\left(20 \mathrm{mg} \mathrm{mL}^{-1}\right.$ trichoderma lysing enzyme and $5 \mathrm{mg} \mathrm{mL}$ ${ }^{-1}$ driselase in $0.8 \mathrm{M} \mathrm{NaCl}$ ) and incubated at room temperature with rotary shaking. After 1-1.5 h, protoplasts were released from hyphae by pipetting with a wide-bore tip then filtered through two layers of sterile miracloth. The filtrate was centrifuged at $1000 \times g$ for $5 \mathrm{~min}$ and the supernatant discarded. The pellet was washed with solution $1\left(0.8 \mathrm{M} \mathrm{NaCl}, 10 \mathrm{mM} \mathrm{CaCl}_{2}\right.$ and $50 \mathrm{mM}$ Tris-HCl, $\mathrm{pH}$ 7.5). The pellet was resuspended in $200-500 \mu \mathrm{L}$ of solution 1 . Then, $100 \mu \mathrm{L}$ of protoplast was mixed gently with 5-10 $\mu \mathrm{g}(10 \mu \mathrm{L})$ of plasmid DNA and incubated on ice 2 min. The mixture was added $1 \mathrm{~mL}$ of solution $2(60 \%$ (w/v) PEG 3350, $0.8 \mathrm{M} \mathrm{NaCl}$, $10 \mathrm{mM} \mathrm{CaCl}_{2}$ and $50 \mathrm{mM}$ Tris- $\mathrm{HCl}, \mathrm{pH}$ 7.5) and incubated for $20 \mathrm{~min}$. Finally, the mixture was added $40 \mathrm{~mL}$ of molten $\left(50^{\circ} \mathrm{C}\right) \mathrm{CZSB}$ and overlaid onto four prepared plates containing $15 \mathrm{~mL}$ of CZST plus appropriate additives (see below). The plates were incubated at $28^{\circ} \mathrm{C}$ for $3-5$ days until colonies appeared.

Selective media for A. oryzae transformation. A volume of $100 \mathrm{~mL}$ of $3.5 \%$ Czapek Dox agar was supplemented with $1 \mathrm{~mL}$ of $20 \%$ ammonium sulphate and 1 $\mathrm{mL}$ of an optional supplement (depending on selection marker of plasmid) such as $0.5 \%$ adenine and/or $1 \%$ methionine and/or $2 \%$ arginine

Nuclear magnetic resonance. NMR was obtained using a Bruker Avance 500 instrument equipped with a cryo-cooled probe at $500 \mathrm{MHz}\left({ }^{1} \mathrm{H}\right)$ and $125 \mathrm{MHz}$ $\left({ }^{13} \mathrm{C}\right) .2 \mathrm{D}$ spectra (COSY, HSQC and HMBC) were obtained using standard parameters. Samples were dissolved in the indicated solvents. ${ }^{1} \mathrm{H}$ and ${ }^{13} \mathrm{C}$ spectra are referenecd relative to residual protonated solvent. All $\delta$ values are quoted in ppm and all $J$ values in $\mathrm{Hz}$.

\section{Data availability}

All NMR data, details of cloning procedures, detailed LCMS chromatograms and details of bioinformatic procedures and results are contained in the Supplementary Information. The strobilurin BGC is deposited at GenBank with accession number KY070339. All other data are available from the authors upon reasonable request.

Received: 16 May 2018 Accepted: 24 August 2018

Published online: 26 September 2018

\section{References}

1. Anke, T., Oberwinkler, F., Steglich, W. \& Schramm, G. Strobilurins-new antifungal antibiotics from Basidiomycete Strobilurus tenacellus. J. Antibiot. 30, 806-810 (1977)

2. Anke, T., Hecht, H. J., Schramm, G. \& Steglich, W. Antibiotics from Basidiomycetes 9. Oudemansin, an antifungal antibiotic from Oudemansiella mucida. J. Antibiot. 32, 1112-1117 (1979).

3. Becker, W., Vonjagow, G., Anke, T. \& Steglich, W. Oudemansin, strobilurinA, strobilurin-B and myxothiazol-new inhibitors of the $\mathrm{Bcl}$ segment of the respiratory-chain with an $E$-beta-methoxyacrylate system as common structural element. FEBS Lett. 132, 329-333 (1981). 
4. Bartlett, D. W. et al. The strobilurin fungicides. Pest Manag. Sci. 58, 649-662 (2002).

5. Sauter, H., Steglich, W. \& Anke, T. Strobilurins: evolution of a new class of active substances. Angew. Chem. Int. Ed. 38, 1329-1349 (1999).

6. Clough, J. The strobilurins, oudemansins, and myxothiazols, fungicidal derivatives of beta-methoxyacrylic acid. Nat. Prod. Rep. 10, 565-574 (1993).

7. Fredenhagen, A., Kuhn, A., Peter, H., Cuomo, V. \& Giuliano, U. Strobilurin-F, strobilurin-G and strobilurin- $\mathrm{H}, 3$ new antifungal metabolites from Bolinea lutea 1. fermentation, isolation and biological-activity. J. Antibiot. 43, 655-660 (1990).

8. Fredenhagen, A., Hug, P. \& Peter, H. Strobilurin-F, strobilurin-G and strobilurin- $\mathrm{H}, 3$ new antifungal metabolites from Bolinea lutea 2. Structure determination. J. Antibiot. 43, 661-667 (1990).

9. Bedford, C. T., Perry, D. \& Sharma, R. K. Bolineol, a novel co-metabolite of strobilurins A, F and G from Bolinea lutea. Nat. Prod. Res. 22, 1535-1539 (2008).

10. Iqbal, Z. et al. Investigations into the biosynthesis of the antifungal strobilurins. Org. Biomol. Chem. 16, 5524-5532 (2018).

11. Nerud, F., Sedmera, P., Zouchová, Z., Musílek, V. \& Vondráček, M. Biosynthesis of mucidin, an antifungal antibiotic from Basidiomycete Oudemansiella mucida ${ }^{2} \mathrm{H}-,{ }^{13} \mathrm{C}$ - and ${ }^{14} \mathrm{C}$-labelling study. Coll. Czech. Chem. Commun. 47, 1020-1025 (1982).

12. Cox, R. Polyketides, proteins and genes in fungi: programmed nano-machines begin to reveal their secrets. Org. Biomol. Chem. 5, 2010-2026 (2007).

13. Blin, K. et al. antiSMASH 4.0-improvements in chemistry prediction and gene cluster boundary identification. Nucleic Acids Res. 45, W36-W41 (2017). $1-6$.

14. Zhou, Y. et al. Resistance mechanisms and molecular docking studies of four novel QoI fungicides in Peronophythora litchii. Sci. Rep. 5, 1-10 (2015).

15. Kraiczy, P. et al. The molecular basis for the natural resistance of the cytochrome bc1 complex from strobilurin-producing Basidiomycetes to center Qp inhibitors. Eur. J. Biochem. 235, 54-63 (1996).

16. Skiba, M. A. et al. Domain organization and active site architecture of a polyketide synthase C-methyltransferase. ACS Chem. Biol. 11, 3319-3327 (2016).

17. Cox, R. J. et al. Rapid cloning and expression of a fungal polyketide synthase gene involved in squalestatin biosynthesis. Chem. Commun. (Camb.) https:// doi.org/10.1039/b411973h (2004)

18. Halo, L. M. et al. Late stage oxidations during the biosynthesis of the 2pyridone tenellin in the entomopathogenic fungus Beauveria bassiana. J. Am. Chem. Soc. 130, 17988-17996 (2008).

19. Pahirulzaman, K., Williams, K. \& Lazarus, C. M. A toolkit for heterologous expression of metabolic pathways in Aspergillus oryzae. Methods Enzymol. 517, 241-260 (2012).

20. Song, Z. et al. Heterologous expression of the avirulence gene ACE1 from the fungal rice pathogen. Magnaporthe oryzae. 6, 4837-4845 (2015).

21. Lazarus, C. M., Williams, K. \& Bailey, A. M. Reconstructing fungal natural product biosynthetic pathways. Nat. Prod. Rep. 31, 1339-1347 (2014).

22. Jin, F. J., Maruyama, J.-I., Juvvadi, P. R., Arioka, M. \& Kitamoto, K. Development of a novel quadruple auxotrophic host transformation system by $\arg B$ gene disruption using adeA gene and exploiting adenine auxotrophy in Aspergillus oryzae. FEMS Microbiol. Lett. 239, 79-85 (2004).

23. Fujii, T., Yamaoka, H., Gomi, K., Kitamoto, K. \& Kumagai, C. Cloning and nucleotide sequence of the ribonuclease T1gene ( $r n t \mathrm{~A})$ from Aspergillus oryzae and its expression in Saccharomyces cerevisiae and Aspergillus oryzae. Biosci. Biotechnol. Biochem. 59, 1869-1874 (1995).

24. Yamada, O. et al. dffA gene from Aspergillus oryzae encodes L-ornithine N-5oxygenase and is indispensable for deferriferrichrysin biosynthesis. J. Biosci. Bioeng. 95, 82-88 (2003).

25. Tsuchiya, K. et al. Deletion analysis of the Taka-amylase-A gene promoter using a homologous transformation system in Aspergillus oryzae. Biosci. Biotechnol. Biochem. 56, 1849-1853 (1992).

26. Kim, M. I., Kwon, S. J. \& Dordick, J. S. In vitro precursor-directed synthesis of polyketide analogues with coenzyme A regeneration for the development of antiangiogenic agents. Org. Lett. 11, 3806-3809 (2009).

27. Prantz, K. \& Mulzer, J. Decarboxylative Grob-type fragmentations in the synthesis of trisubstituted $Z$-olefins: application to peloruside A, discodermolide, and epothilone D. Angew. Chem. Int. Ed. 48, 5030-5033 (2009).

28. Grigorieva, N. Y., Popovsky, V. A., Stepanov, A. V. \& Lubuzh, E. D. Formal synthesis of strobilurins A and X. Russ. Chem. Bull. 59, 2086-2093 (2010).

29. Kuehnel, E. et al. Mechanism of methyl esterification of carboxylic acids by trimethylsilyldiazomethane. Angew. Chem. Int. Ed. 46, 7075-7078 (2007).
30. Bonsch, B. et al. Identification of genes encoding squalestatin S1 biosynthesis and in vitro production of new squalestatin analogues. Chem. Commun. 52, 6777-6780 (2016)

31. Liu, N. et al. Identification and heterologous production of a benzoyl-primed tricarboxylic acid polyketide intermediate from the zaragozic acid A biosynthetic pathway. Org., Lett. 19, 3560-3563 (2017).

32. Kennedy, J. et al. Modulation of polyketide synthase activity by accessory proteins during lovastatin biosynthesis. Science 284, 1368-1372 (1999).

33. Halo, L. M. et al. Authentic heterologous expression of the tenellin iterative polyketide synthase nonribosomal peptide synthetase requires coexpression with an enoyl reductase. Chembiochem 9, 585-594 (2008).

34. Bailey, A. M. et al. Characterisation of 3-methylorcinaldehyde synthase (MOS) in Acremonium strictum: first observation of a reductive release mechanism during polyketide biosynthesis. Chem. Commun. (Camb.) 0, 4053-4055 (2007).

35. Song, Z., Cox, R., Lazarus, C. \& Simpson, T. Fusarin C biosynthesis in Fusarium moniliforme and Fusarium venenatum. Chembiochem 5, 1196-1203 (2004).

36. Hang, L. et al. Reversible product release and recapture by a fungal polyketide synthase using a carnitine acyltransferase domain. Angew. Chem. Int. Ed. $\mathbf{5 6}$ 9556-9560 (2017).

37. Kandziora, N. et al. Uncovering the origin of $Z$-configured double bonds in polyketides: intermediate $E$-double bond formation during borrelidin biosynthesis. Chem. Sci. 5, 3563-3567 (2014).

38. He, H.-Y., Tang, M.-C., Zhang, F. \& Tang, G.-L. Cis-Double bond formation by thioesterase and transfer by ketosynthase in FR901464 biosynthesis. J. Am. Chem. Soc. 136, 4488-4491 (2014).

39. Shah, D. D., You, Y.-O. \& Cane, D. E. Stereospecific Formation of $E$ - and $Z$ disubstituted double bonds by dehydratase domains from modules 1 and 2 of the fostriecin polyketide synthase. J. Am. Chem. Soc. 139, 14322-14330 (2017).

40. Xie, X. \& Cane, D. Stereospecific formation of Z-trisubstituted double bonds by the successive action of ketoreductase and dehydratase domains from trans-AT polyketide synthases. Biochemistry 57, 3126-3129 (2018).

41. Liddle, E. et al. In vitro kinetic study of the squalestatin tetraketide synthase dehydratase reveals the stereochemical course of a fungal highly reducing polyketide synthase. Chem. Commun. 53, 1727-1730 (2017).

42. Ahmed, S. A. et al. Biosynthesis of aspyrone and asperlactone, pentaketide metabolites of Aspergillus melleus. Incorporation studies with $\left[1-{ }^{13} \mathrm{C},{ }^{18} \mathrm{O}_{2}\right]$ acetate and ${ }^{18} \mathrm{O}_{2}$ gas. J. Chem. Soc. Chem. Commun. 0, 1685-1687 (1985).

43. Hanson, K., O’Neill, J. A., Simpson, T. J. \& Willis, C. L. Bartanol and bartallol, novel macrodiolides from Cytospora sp. ATCC 20502. J. Chem. Soc. Perk. Trans. 1, 2493-2495 (1994).

44. Raggatt, M. E., Simpson, T. J. \& Chicarelli-Robinson, M. I. Biosynthesis of Xenovulene $\mathrm{A}^{\oplus}$ : formation of a cyclopentenone via a unique ring expansionring contraction mechanism. Chem. Commun. (Camb.) 0, 2245-2246 (1997).

45. Schor, R., Schotte, C., Wibberg, D., Kalinowski, J. \& Cox, R. J. Three previously unrecognised classes of biosynthetic enzymes revealed during the production of xenovulene A. Nat. Commun. 9, 1963 (2018).

46. He, Y. \& Cox, R. J. The molecular steps of citrinin biosynthesis in fungi. Chem. Sci. 7, 2119-2127 (2016).

47. Zhao, Y., Such, P. \& Retey, J. Radical intermediates in the coenzyme B12 dependent methylmalonyl-CoA mutase reaction shown by ESR spectroscopy. Angew. Chem. Int. Ed. 31, 215-216 (1992).

48. Sandala, G. M., Smith, D. M. \& Radom, L. The carbon-skeleton rearrangement in tropane alkaloid biosynthesis. J. Am. Chem. Soc. 130, 10684-10690 (2008).

49. Nasomjai, P. et al. Mechanistic insights into the cytochrome P450-mediated oxidation and rearrangement of littorine in tropane alkaloid biosynthesis. Chembiochem 10, 2382-2393 (2009).

50. Robinson, M. W. C., Pillinger, K. S. \& Graham, A. E. Highly efficient Meinwald rearrangement reactions of epoxides catalyzed by copper tetrafluoroborate. Tetrahedron Lett. 47, 5919-5921 (2006).

\section{Acknowledgements}

R.N. thanks the Directorate General of Resources for Science and Higher Education (Beasiswa Pendidikan Pascasarjana Luar Negeri Direktorat Jenderal Sumber Daya Ilmu Pengetahuan dan Pendidikan Tinggi (BPP-LN Ditjen SD Iptek-Dikti)), Republic of Indonesia, for an Overseas Postgraduate Scholarship and the Alumni foundation of the University of Bristol for financial support. K.d.M.-S. was funded by BBSRC (BB/ K002341/1) and L.-C.H. by BBSRC and EPSRC through BrisSynBio and the Centre for Synthetic Biology (BB/L01386X/1). Z.I. thanks the Higher Education Commission of Pakistan for a post-graduate scholarship. We thank EPSRC (EP/F066104/1) and DFG (INST 187/621-1) for LCMS equipment, BBSRC for culture facilities (BB/L01386X/1) and the University of Bristol Genomics Facility for DNA and RNA sequencing. K.E.L. was funded by the Leibniz University of Hannover. R.J.C. thanks Dr. John Clough and 
Dr. Katherine Williams for helpful discussions, and Jennifer Senkler (Leibniz Universität) for protein MS analysis.

\section{Author contributions}

R.J.C. and T.J.S. designed the study and wrote the manuscript. R.N. and Z.I. fermented the fungi and performed the natural product analysis. A.M.B., R.N. and K.d.M.-S. performed the genome and transcriptome sequence, analysis and interpretation. R.N., K.d. M.S. and K.E.L. performed the cloning and heterologous expression. R.N. and K.E.L. performed the compound isolation, analysis and structure elucidation. L.-C.H. performed all synthetic procedures. L.C.H., Z.I., R.N. and K.E.L. were supervised by R.J.C., T.J.S., C.L.W. and A.M.B. All authors revised the MS.

\section{Additional information}

Supplementary Information accompanies this paper at https://doi.org/10.1038/s41467018-06202-4

Competing interests: The authors declare no competing interests.

Reprints and permission information is available online at http://npg.nature.com/ reprintsandpermissions/
Publisher's note: Springer Nature remains neutral with regard to jurisdictional claims in published maps and institutional affiliations.

cc (i) Open Access This article is licensed under a Creative Commons Attribution 4.0 International License, which permits use, sharing, adaptation, distribution and reproduction in any medium or format, as long as you give appropriate credit to the original author(s) and the source, provide a link to the Creative Commons license, and indicate if changes were made. The images or other third party material in this article are included in the article's Creative Commons license, unless indicated otherwise in a credit line to the material. If material is not included in the article's Creative Commons license and your intended use is not permitted by statutory regulation or exceeds the permitted use, you will need to obtain permission directly from the copyright holder. To view a copy of this license, visit http://creativecommons.org/ licenses/by/4.0/.

(C) The Author(s) 2018 